\title{
'EGGS MAKE KIDS': A MARKET-DRIVEN APPROACH TO PROMOTE EGGS AS A NUTRITIOUS FOOD FOR YOUNG CHILDREN IN NIGERIA
}

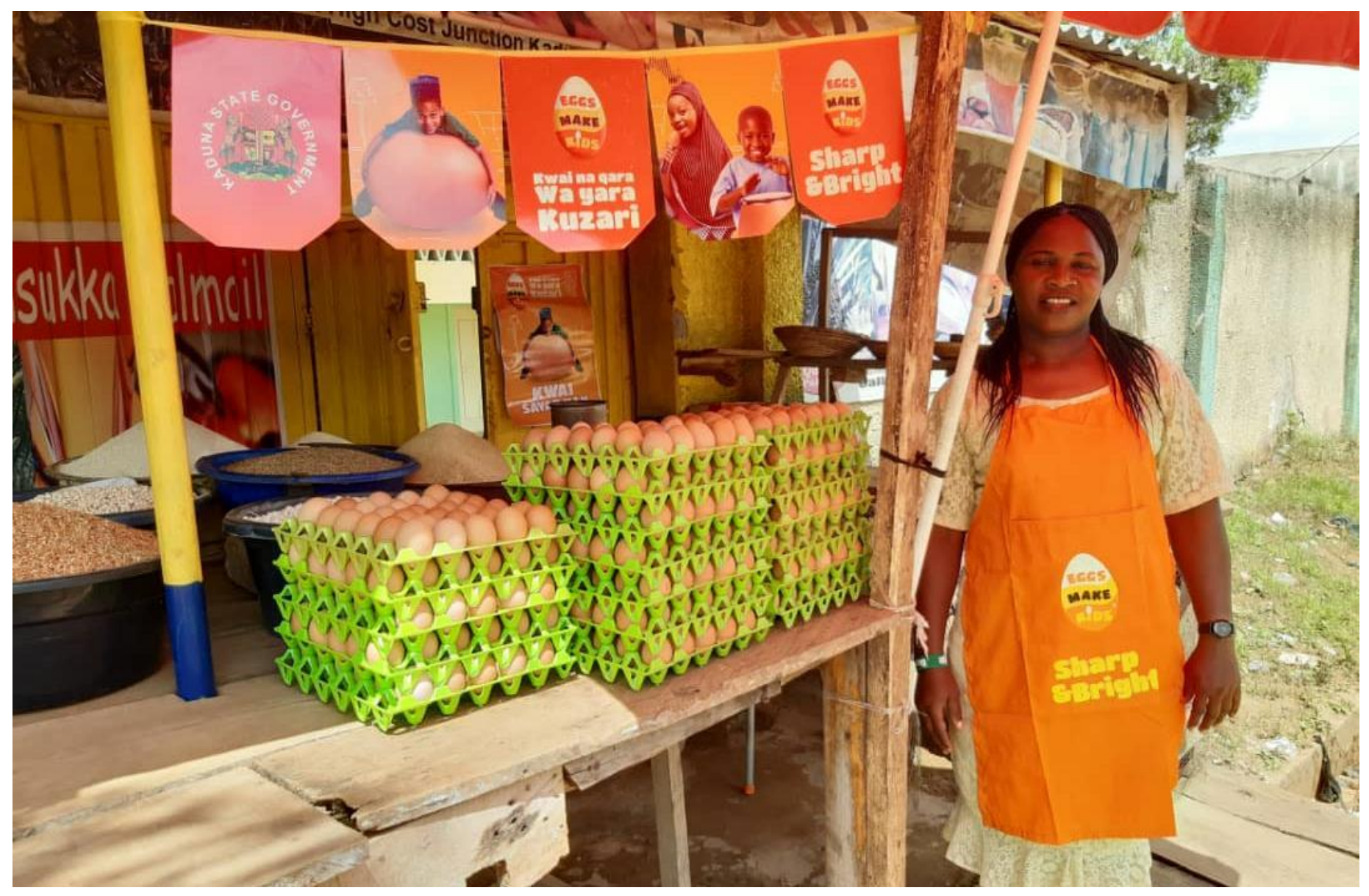

GAIN Working Paper n¹0

October, 2020

Emily LaRose, Miriam Shindler, Irowa Erhabor, Alia Poonawala, Ashish Deo, Michael Ojo, Wendy Gonzalez, Abigail Falla

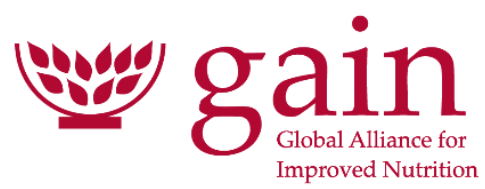




\section{ABOUT GAIN}

The Global Alliance for Improved Nutrition (GAIN) is a Swiss-based foundation launched the UN in 2002 to tackle the human suffering caused by malnutrition. Working with governments, businesses and civil society, we aim to transform food systems so that they deliver more nutritious food for all people, especially the most vulnerable.

\section{Recommended citation}

LaRose E, Erhabor I, Shindler M, Poonawala A, Deo A, Ojo M, Gonzalez W, and Falla A. Eggs Make Kids: A market-driven approach to promote eggs as a nutritious food for young children in Nigeria. Global Alliance for Improved Nutrition (GAIN). Working Paper \#10. Geneva, Switzerland, 2020. DOI: https://doi.org/10.36072/wp.10

\section{(C) The Global Alliance for Improved Nutrition (GAIN)}

This work is available under the Creative Commons Attribution-Non-Commercial-Share Alike 4.0 IGO licence (CC BY-NC-SA 4.0 IGO; https://creativecommons.org/licenses/by-nc-sa/4.0/). Under the terms of this licence, you may copy, redistribute, and adapt the work for non-commercial purposes, provided the work is appropriately cited, as indicated below. In any use of this work, there should be no suggestion that GAIN endorses any specific organisation, products or services. The use of the GAIN logo is not permitted. If you adapt the work, then you must license your work under the same or equivalent Creative Commons license. The contributions of third parties do not necessarily represent the view or opinion of GAIN.

\section{Acknowledgements}

GAIN is grateful for the support and participation of all of those who helped to design and implement the 'Eggs Make Kids' project. The authors also wish to thank the following individuals for participating in qualitative interviews to support the writing of this paper: Chris Holmes, Independent Project Design Consultant (GAIN); Tracey Afuwape, Business Unit Director, PHD Media, Nigeria; Rotimi Olasupo and Abdulahi Abiodun, Marketing Operations Managers, and Topa Simon, Implementation Officer, GDM Group, Nigeria. We gratefully acknowledge the financial support of the Dutch Ministry of Foreign Affairs for this project and the Making Markets Work donors. All photographs included in this document have been taken with consent for use in publications.

\section{GAIN WORKING PAPER SERIES}

The GAIN Working Paper Series provides informative updates on programme approaches and evaluations, research, and other topics relevant to helping reshape the food system to improve the consumption of nutritious, safe food for all people, especially the most vulnerable.

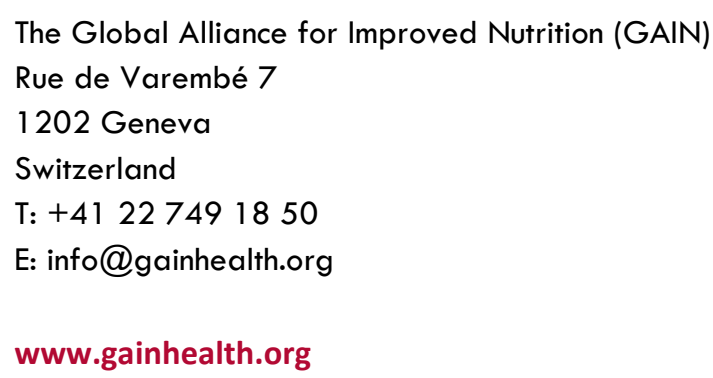




\section{SUMMARY}

Improving dietary diversity and ensuring adequate availability and intake of nutritious foods are vital to give children the best possible start in life. In Kaduna State, Nigeria, few young children meet the international standards for dietary diversity, and childhood undernutrition is widespread. Eggs are a widely available and affordable source of protein, vitamins, and minerals that support growth and development, yet they are not frequently fed to children in Kaduna. The 'Eggs Make Kids' campaign was launched by GAIN on World Egg Day in October 2019. Using commercial marketing techniques and insights into consumer behaviour, it aims to create demand for eggs as a nutritious food for children aged six months to five years.

The campaign encourages parents to feed children at least two eggs per week. With support and engagement from the Kaduna State government, the Poultry Association of Nigeria, egg vendors, and creative agencies, the campaign utilises multiple communication channels to create a strong emotional appeal to increase caregivers' willingness to buy eggs and feed them to their children. Several important lessons were learned while testing this new model that should be considered in future campaigns. There are limitations to using egg sales trends for monitoring due to factors including a lack of historical sales data, seasonality, and price fluctuations. Working with creative agencies requires a new style of partnership management, and real-time monitoring allows for agility when challenges arise. There is also a critical need for early baseline assessment and access to current, local data.

This project was feasible because of strong institutional support, established egg supply, and an existing poultry aggregation network. Such issues must be factored in when considering the transferability of the approach to another location, or to other unbranded foods. The "Eggs Make Kids" campaign will be evaluated via a rigorous impact evaluation. Whilst that has not yet been completed, the campaign offers an example of a promising opportunity to improve children's diets and support local food systems by promoting fresh, nutrient-dense foods.

\section{KEY MESSAGES}

- Prevention of undernutrition in children under five years of age is critical to promote normal growth and development, and eggs have been shown to improve growth in some contexts when fed as part of a child's regular diet.

- GAIN thus set out to develop a novel demand-creation campaign to promote egg consumption by young children through the public application of commercial marketing techniques by using diverse communication channels to facilitate targeted messaging.

- Successful demand creation campaigns require a supportive environment with adequate food supply or parallel efforts to build and stabilise such supply, and evidence that consumers can afford to buy the food product.

- While the programme is ongoing and outcomes have not yet been evaluated, there is a considerable opportunity to explore further demand creation activities for fresh, unbranded, nutritious foods to improve diets. 


\section{BACKGROUND AND OBJECTIVE}

Commercial marketing has considerably shaped consumer food demand by using messaging and cognitive appeals that emotionally engage consumers, creating a personal connection with a brand. This approach typically assumes that consumer decision making is based on emotions, choosing to buy products that they find exciting, comforting, safe, or special rather than based on rational benefits $(1,2)$.

Non-commercial campaigns have also been used as a public health approach to promote healthy eating. However, many of these campaigns have merely translated into educational communication, and their impact on actual behaviour tends to be limited, largely short-term, and insufficiently effective (3). Advertising campaigns, including the 'Got Milk? ${ }^{\circledR \prime}$ campaign in the U.S. ${ }^{1}$ (4) or the recent 'Eat Them to Defeat Them' campaign in the U.K. ${ }^{2}$ (5), have used similar tactics to increase consumer demand for unbranded ${ }^{3}$, nutritious foods. These campaigns go beyond stating the health benefits of eating a certain food to emotionally engage consumers, aiming to make a personal connection with that food. For example, 'Eat Them to Defeat Them' plays into children's desires to be superheroes and allows them to imagine themselves as superheroes, defeating vegetables by eating them.

However, there are few examples of these methodologies being employed to create demand for nutritious food consumption in low- and middle-income countries. The Global Alliance for Improved Nutrition (GAIN) hypothesised that using commercial marketing techniques to promote nutritious foods commonly available in local markets and kiosks in Kaduna State, Nigeria could influence purchasing and consumption behaviours. As such, GAIN designed the 'Eggs Make Kids' campaign as a novel demand-creation model to engage caregivers motivating them to purchase and feed their children eggs, a nutritious animal-source food.

In this paper we will discuss how commercial marketing techniques can be used to emotionally engage caregivers to feed eggs to children by presenting the design, progress, and lessons learned from the implementation of the 'Eggs Make Kids' campaign. Given the unprecedented challenges presented by the COVID-19 pandemic, which began during the campaign's implementation, we will also explain how the project was adapted to keep food markets working and eggs accessible to families.

\section{WHAT PROBLEM WAS THE CAMPAIGN AIMING TO SOLVE?}

Despite considerable progress, child undernutrition in low- and middle-income countries remains a widespread concern. While the prevalence of stunting (i.e. children who are too short for their age, an indicator of chronic undernourishment) has been slowly decreasing globally over the past 20 years, stunting in West and Central Africa continues to rank among the worst globally, with more than $30 \%$ of children under five years of age still affected. Wasting (low weight for height) also impacts an estimated 47 million children globally, with

\footnotetext{
${ }^{1}$ The 'Got Milk?" campaign was started in 1993 by the California Milk Processor Board to encourage cows' milk consumption in the U.S.

2 The 'Eat Them to Defeat Them' campaign started in 2020 by Veg Power (an alliance of adverting, retail, nutrition, and culinary experts) and uses advertising to inspire kids to eat more vegetables.

3 Unbranded foods, including household staples like eggs, milk, and fruits and vegetables. In low- and middle-income countries, such foods are often sold loose by vendors sold in markets and kiosks.
} 
heavy concentration in Africa and Southeast Asia (6-8). Nigeria is no exception to this trend. Though there are significant differences among the country's states and regions, according to 2018 national data, 37\% of Nigerian children are stunted (8), with the highest prevalence present in the North West (52.1\%), where Kaduna State lies. Additionally, 7\% of Nigerian children are wasted, with the prevalence also being particularly high in the North West (8.3\%) (9).

Undernutrition in young children significantly contributes to impaired cognitive ability, increased incidence of infection, and increased risk of death (6). Early-life nutrition is particularly critical for growth and development. Optimal practices include exclusive breastfeeding until six months of age, followed by continued breastfeeding until at least two years of age along with age-appropriate complementary foods; such a diet has been shown to reduce the incidence of stunting in young children (10). Beginning at six months of age, the World Health Organization (WHO) recommends offering infants and young children a variety of foods, with animal-source foods (ASFs; i.e., dairy products, fish, meat, poultry, eggs) and vitamin A-rich foods (e.g., carrots, orange-fleshed sweet potatoes, leafy greens) eaten daily, or as often as possible. Indeed, dietary diversity and consumption of ASFs have been shown to be protective against stunting (11). However, insufficient food quantity and poor diet quality remain persistent threats to early childhood growth and development $(12)^{4}$.

\title{
WHY EGGS?
}

One food with high potential for improving diet quality is eggs. As a concentrated source of protein, calories, and fat, in addition to vitamins, minerals, and other compounds, eggs have the potential to make a significant nutritional impact in young children. The nutritional content of the egg white and yolk are shown in Figure 1.

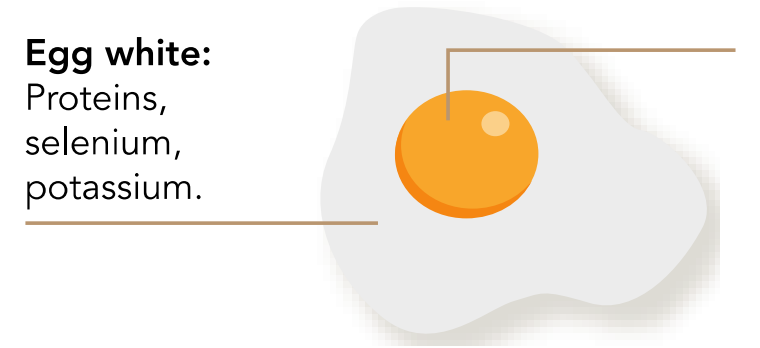

\author{
Egg yolk: \\ Energy, proteins, choline, \\ riboflavin, pantothenic \\ acid, vitamin B6, vitamin \\ B12, folate, phosphorous, \\ selenium.
}

Figure 1: Eggs have two main parts: the egg white and the egg yolk. Both the white and the yolk provide valuable nutrients for both children and adults (reproduced from the GAIN Nutrition of Eggs factsheet (15)).

While the potential impact of eggs on early development has not been confirmed (15), there are a number of pivotal studies that have highlighted the significant benefits of egg consumption on young child growth globally. In a 2017 randomised controlled trial, lannotti et al found that when eggs were fed daily to rural, indigenous Ecuadorian children between

\footnotetext{
${ }^{4}$ Ensuring adequate fat consumption and limiting fruit juices and dietary sugars are also critical $(13,14)$.
} 
six and nine months of age for the six-month study period, both length-for-age and weightfor-age z scores improved and stunting was reduced by $47 \%$ (16). Two years following the intervention, the positive growth impacts found during the study period were lost, but the research team noted that the children in the intervention group were more likely to continue consuming eggs and the children's current egg intake was associated with reduced growth faltering. They concluded that while egg intake does prevent stunting in early life, ongoing investment and attention are needed to continue to support growth during childhood (17).

Other studies have yielded similar results. In a school-based approach in rural Uganda, Baum et al studied the impact of egg consumption on the growth of children between six and nine years of age and found that daily egg intake was associated with improved growth parameters (18). Finally, in a recent study conducted in rural Malawi, consumption of one egg per day did not impact linear growth for children aged six to nine months, but researchers noted that this result may have been significantly influenced by a background diet inclusive of multiple ASFs and a low prevalence of stunting in the study population (19).

Egg affordability, availability, and desirability vary considerably. In low- and middle-income countries, eggs can be scarce because of limited production, distribution, and other challenges. GAIN has a longstanding history of supporting small- and medium-sized enterprises in Africa to produce, supply, and sell nutritious foods, including eggs. Using country-level data and quantitative modelling techniques, Morris et al demonstrated the potential benefits of employing aggregation of egg production to increase egg availability in rural communities. Their research suggested that changing production methods would lower prices and promote increased egg consumption (20).

While macro-level estimates suggest that eggs are not a highly affordable source of protein, vitamins, and minerals in low-income countries (21), formative research conducted by GAIN and its partner organisations identified that eggs are widely available, affordable, acceptable, and accessible in markets and stores specifically in the geography in focus for the work described here (Kaduna State, Nigeria), though they were commonly eaten by men in settings outside the family home. Eggs were not commonly fed to children, or were given to sick children as medicine to help recovery from illness. Qualitative interviews also demonstrated some existing myths or taboos surrounding feeding children eggs. Given sufficient supply, the assumption was that the primarily obstacle to children eating eggs as a readily available ASF was low desire from caregivers. GAIN thus aimed to explore whether this could be addressed through targeted campaigns aimed at generating enthusiasm about the benefits of eggs for children and increasing consumer demand for eggs in local markets. To date, however, studies have not explored how market-driven, demand-creation activities can influence egg purchasing and consumption patterns.

\section{METHODOLOGY}

This working paper was developed via a review of internal materials in combination with a series of semi-structured, qualitative interviews with key stakeholders. Internal materials include baseline assessments, survey data, creative concept tests, programme tools, and 
programme evaluation tools and techniques. Scientific databases were searched to identify relevant published literature for the background and supporting information.

Interviewees included GAIN staff members, GAIN consultants, and representatives from government and partner organisations. The goal of the interviews was to fully explore the process of developing the egg demand-creation campaign, from early ideation through to implementation, and to generate lessons learned. Qualitative interview guides were developed with targeted questions for each participant. All interviews were conducted virtually and recorded to ensure that their content was available for later reference. All participants provided consent to be interviewed, and verbal permission was obtained prior to recording.

Background and supporting information were gathered via PubMed, employing keyword searches for publications on nutrition, egg consumption, early childhood feeding, and complementary feeding. Literature searches were limited to the past five years unless a paper appeared to be of particular significance, as evidenced by frequent referencing by other articles. Abstracts were reviewed for relevance and full-text papers (in English) were considered for inclusion if they explored the impact of egg consumption on early child growth and development. Additional supplementary information was obtained from reports from governmental agencies, the WHO, and the Food and Agriculture Organisation of the United Nations (FAO).

\section{PROGRAMMATIC OVERVIEW}

In 2017, GAIN sought to determine if and how a product marketing approach could create demand for unbranded nutritious foods to improve diets for children under five years of age. Product marketing for unbranded foods is challenging because the foods can be perceived as common, and, unlike large food manufacturers, farmers and vendors lack the resources (i.e., budget, packaging, or marketing specialists) to develop consumer campaigns. When deciding what commodity to target, GAIN explored options to fill dietary gaps in high-quality protein and iron that had been identified in earlier formative studies. Dairy products (i.e., milk), meat (i.e., chicken, beef), and eggs were all considered as candidates for such an approach.

Each food product was evaluated for seasonality, acceptability, palatability, and current consumption patterns using national survey data, qualitative data, and contextual knowledge of staff and partner agencies. Government priorities and social norms and taboos relating to each food product were also considered. Dairy milk was excluded because it introduced complexities with food safety (i.e., ensuring a cold chain or managing risks associated with rehydration of powdered milk with unsafe water) and a concern that dairy milk, if promoted to young children, could be incorrectly perceived as a substitute for breastmilk. Meats (i.e., chicken, beef) were also associated with food safety concerns and did not meet the established threshold for affordability. The data were then used to evaluate which of the foods were both culturally acceptable and palatable but less frequently consumed. 
Eggs were found to be easily accessible all year round and were considered palatable, with many families reporting occasional egg intake, often outside of the home. An affordability analysis using economic modelling of household income confirmed that a target of least $70 \%$ of households could afford two eggs a week for each child, based on assumptions that each household had an estimated three to five children.

Data supported GAIN's rationale for a demand-creation approach: limited egg consumption among children was shown to be related to a lack of caregiver awareness of affordability and nutritional benefits. Other supporting factors for the selection of eggs as the focus of a demand-creation project in Kaduna State included national government investment in the poultry value chain to increase accessibility and sustainability of the egg supply, an opportunity to align with partner programmes, including the Alive and Thrive infant and young child feeding (IYCF) programmes in the country, and the broad awareness of the Nigerian government's school-based National Egg Production initiative, which provides one egg per week to children between five and nine years old.

\section{WHY KADUNA STATE?}

Situated in the North West region of Nigeria, Kaduna State has over 1.6 million children under the age of five and ranks high, compared to other states, in its prevalence of stunting and wasting. According to the 2017 Nigeria National Bureau of Statistics Multiple Cluster Survey, $47 \%$ of children under age five are stunted, $12 \%$ suffer from wasting, and $34 \%$ are underweight (22).

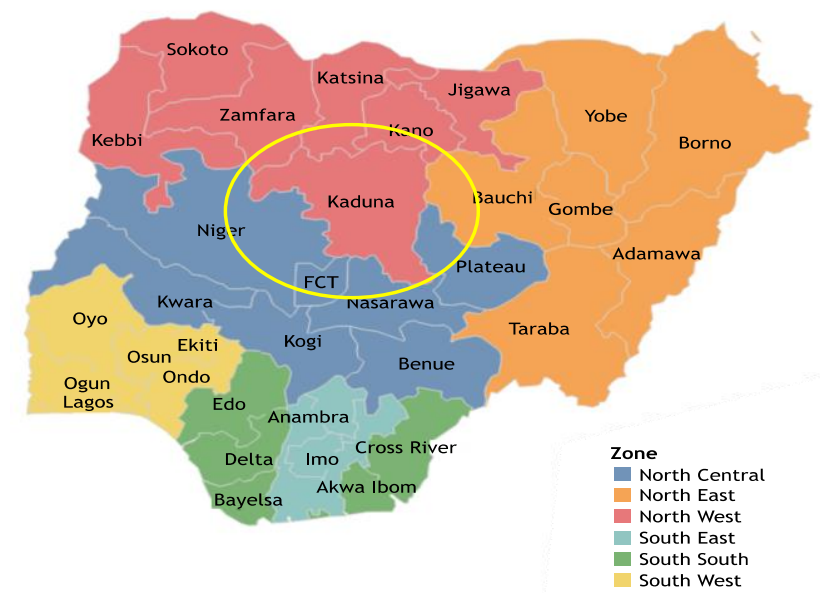

Figure 2: Map of Nigeria showing states and division by geopolitical zone. Kaduna State is part of the North West region of the nation. Graphic obtained from the 2018 Nigerian National Nutrition and Health Survey Report (5).

Kaduna State also ranks low in terms of dietary indicators. According to the 2016 Nigeria Food Security and Vulnerability Survey report, about $41 \%$ of households in Kaduna State consumed fewer than five food groups ${ }^{5}$ in the 24 hours prior to the survey (24). Similarly, the

\footnotetext{
${ }^{5}$ Food groups refer to the seven food groups recommended by the WHO: grains, roots, and tubers; legumes and nuts; dairy products, including milk, cheese, yogurt; flesh foods, including meat, fish, poultry, and organ meats; eggs; vitamin-A rich fruits and vegetables; and other fruits and vegetables (23).
} 
2018 Nigerian Demographic and Health Survey (DHS) found that only $15.6 \%$ of children between six and 23 months of age meet dietary diversity standards ${ }^{6}$ and only $13.9 \%$ receive a minimally acceptable diet $^{7}$ needed to support growth and development (25). At the national level, the DHS found that only $12.7 \%$ of children six to 23 months had consumed eggs in the day preceding the survey interview (25). The DHS does not provide disaggregated egg consumption data for Kaduna State.

Though neighbouring Kebbi State was also evaluated, Kaduna State was selected for this project because of the positive enabling environment that it provided to support this project, as further detailed in Box 1.

\section{BOX 1: KEY ASPECTS OF THE ENABLING ENVIRONMENT IN KADUNA STATE}

- Nutrition as a State Priority: Launched in January 2017 by Kaduna State, the Kaduna Emergency Nutrition Action Plan (KENAP) is tasked with decreasing the prevalence of malnutrition and stunting in the state.

- Existing IYCF Programming: With the support of the Government of Nigeria, Alive \& Thrive had an existing social and behaviour change campaign that emphasised early and exclusive breastfeeding as well as dietary diversity in Kaduna State. This provided a unique opportunity for GAIN to build on an existing campaign, emphasise eggs as an ASF, and harmonise IYCF messages.

- Egg Supply: In addition to a large hatchery that sells eggs to neighbouring states, Kaduna State maintains a network of smallholder farmers that support and provide a stable egg supply that is widely available in local markets.

- Poultry Aggregators: With the support of the National Home-Grown School Feeding Programme, poultry aggregators are improving the livestock industry and supporting schools to provide nutritious meals to children. Distribution and logistic support are provided to farmers, wholesalers, and vendors via the Poultry Association of Nigeria (PAN) to strengthen the egg value chain.

- Household Income: Affordability studies suggest that about $70 \%$ of the population in Kaduna State could afford to purchase two eggs per child weekly.

- Dietary Acceptability: Baseline surveys found that most families consume eggs on occasion, though few people regularly eat eggs at home. Eggs are most consumed by men in tea houses or cafés, and they are not frequently fed to children because they are not thought of as a 'children's food.'

\footnotetext{
${ }^{6}$ Minimum dietary diversity is defined as a child receiving foods from at least four food groups in the day prior to the survey(23)

7 Minimum meal frequency is defined as meeting a particular threshold for the number of times a child is fed solid foods in the day prior to the survey, with the threshold varying depending on the child's age and breastfeeding status. Minimum acceptable diet is defined as meeting both minimum dietary diversity and minimum meal frequency for the preceding day (23).
} 


\section{PROJECT DESIGN}

The 'Eggs Make Kids' campaign was born from a combination of the known nutritional benefits of eggs, the need improve the diets of young children in Kaduna State, and the opportunity to test a demand-creation model for a nutritious, fresh, and unbranded food. During the project and campaign design, GAIN employed an interdisciplinary approach utilising staff experience in commercial advertising and marketing, creative campaign development, nutrition programming, and project management. GAIN sought to ensure that outcomes were clear, partner and creative agencies were managed effectively, and a successful campaign strategy was developed and launched.

Both international and Nigeria-based creative agencies were hired to develop creative content and to manage the campaign launch and implementation. Interested agencies submitted proposals to develop and test creative concepts, create advertising materials, and propose approaches to campaign implementation across different media and advertising channels. Three implementing partners were hired by GAIN, each with distinct expertise and chosen to deliver a specific part of the campaign under GAIN's supervision and coordination: (1) development of the strategy and creative content, (2) planning and delivery of Above The Line (ATL) activities (i.e., TV, Radio, Billboard, tricycle branding), (3) planning and delivery of Below The Line $(B T L)^{8}$ activities, such as community-based and retail activation?. The differences between ATL and BTL activities are explained in more detail in Box 2 .

\section{BOX 2: CAMPAIGN ACTIVITIES}

\section{State-Wide \\ Above the Line (ATL) Campaign}

- Television spots and cooking shows

- Radio spots, jingles, and dramas

- Tricycle Branding

ATL activities were developed to reach and inform the public through fun and informative engagement. The ATL campaign endeavoured to emotionally engage caregivers and promote caregiver confidence in choosing eggs for their children.

\section{Community-Based \\ Below the Line (BTL) Campaign}

- Point-of-purchase materials

- Neighbourhood, compound, and open market shows

- Primary health care centre promotions

BTL activities were designed to engage consumers personally and prompt consumers to purchase eggs in the market by utilising materials and activities to influence behaviour at the-point-of purchase.

\footnotetext{
${ }^{8}$ ATL and BTL are terms used in advertising and marketing to describe different techniques to reach customers. ATL campaigns use mass media to reach a larger and more general target group whereas BTL campaigns are more targeted and rely on direct communication with customers. A further explanation of the use of ATL and BTL techniques in the 'Eggs Make Kids' campaign can be found in Box 2 .

9 'Retail activation' refers to activities carried out in shops to induce the consumers to buy, e.g. point of sale materials or displays, demonstrations by promoters, price discounts etc.
} 


\section{CAMPAIGN CONCEPT DEVELOPMENT}

Creative concepts were developed by a creative agency, with the overall objective of encouraging caregivers to consider eggs as an everyday, nutritious food for children. Messages were designed to inspire confidence and empower caregivers to choose eggs for their children as well as learn about the benefits of eggs. Six different concepts were developed; these were then audience tested to identify which concept should be further developed into a communication campaign.

The six campaign concepts were as follows:

- Egg, the most affordable gold in the world

- Eggs make them shine and I shine

- Share the goodness with your child

- Eggs make them strong and active, sharp and bright

- Feed your children like royalty, give them eggs

- Superheroes love eggs

These six different concepts were tested among a broad sample of Nigerian adults. Concepts were tested both online (350 participants) and in person (150 rural, low-income participants from Kaduna State). Age and gender distribution were equivalent across the two respondent groups (50\% male/female; $50 \% 18-29$ years of age, $50 \% 30$ years of age or older) and the majority of participants had children in their household (73\% online; $65 \%$ offline).

The concepts were tested adapting the System 1 Predictive Market Test (26). The test begins by asking the primary question: 'What do you think of this idea to get parents to feed their children more eggs?' Participants were asked to report if each concept was a 'good idea' or a 'bad idea' and rate how others would respond emotionally to each idea using an intensity score. The pre-identified emotions scored against included contempt, disgust, anger, fear, sadness, neutral, happiness, and surprise. Participants were then asked to provide comments on the images and messages used in each concept.

Using comparative data from other countries in Africa, participant responses to each concept were assigned a star rating between 1 (worst) and 5 (best). Higher aggregate star ratings indicated the concepts that were considered more emotive and thus more likely to support advertising aimed at improving product sales (28). 
All six scored higher than a one-star rating. The 'Eggs make them strong and active, sharp and bright' theme was the highest ranked among participants and largely elicited feelings of happiness and surprise.

Participants endorsed the universal insight of wanting the best for one's child by suggesting that 'all parents want a strong, bright, sharp, and active child' and 'everyone wants to feel special and very active, and to be recognised as smart.' Participants liked the sample campaign images, colour and visual representation, and commented that, 'the kids look energetic, and it is easy to decipher that this is because of eggs.' While educating families about the nutritional benefits of eggs is a goal of the campaign, suggestions for improvement were centred around campaign information perhaps being common knowledge for some caregivers. Participants suggested that 'eggs are good for kids and their health and they might know already' and 'they actually

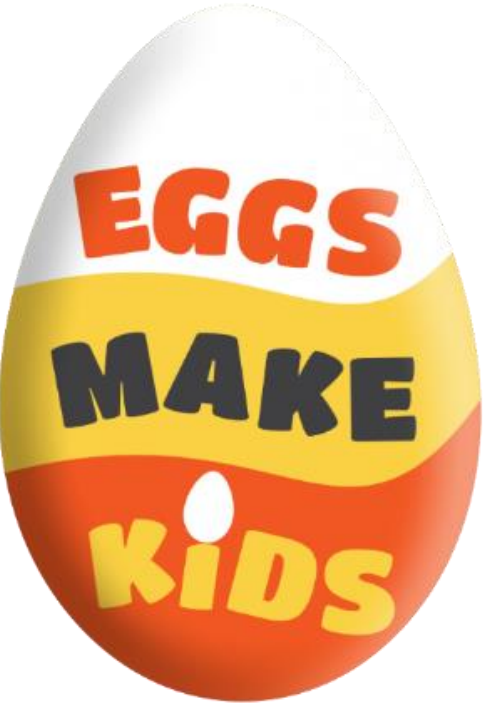

Figure 3: Final campaign logo and tagline know eggs are protein.'

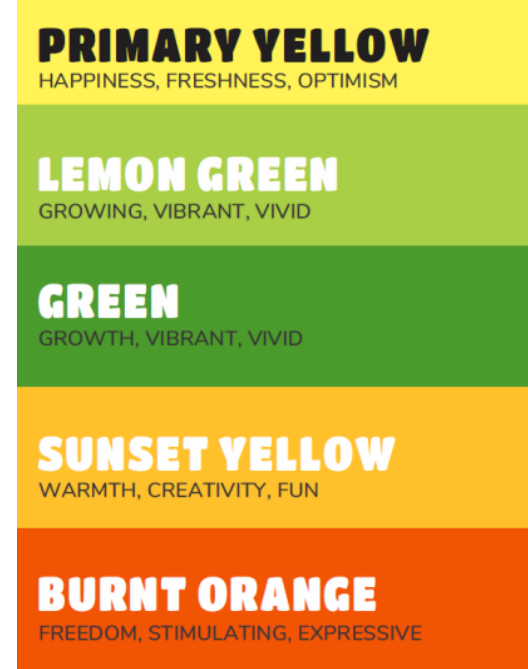

Figure 4: Campaign colours and associated emotions
Printed materials featured the shortened strapline 'Eggs Makes Kids' and a colour palate of yellows, greens, and burnt orange to attract and appeal to caregivers and children alike. Each colour represented an emotion intended to elicit a reaction among caregivers.

Creative photography and illustrative elements brought in humour by using eggs in abstract forms, such as musical instruments and dumbbells. The core concept and fun messaging were also brought to the campaign jingles, which were sung to the tunes of known folklore songs and used traditional musical instruments of the dominant local ethnic group, the Hausa, including the alghaita, kakaki, goje, and others.

\section{COMMUNICATIONS APPROACH TO CREATE DEMAND FOR EGGS}

The ongoing campaign activities use multiple channels to motivate parents and caregivers to purchase eggs to benefit their child(ren). The diversity of communication channels facilitates targeting a range of messages at caregivers using a 360-degree approach, with each channel aimed to deliver on specific communication objectives. This strategy was informed by an indepth understanding of the media consumption habits of the target audience, ensuring investments were made on the most effective channels to deliver the right messages to the 
target group. The messages, whether on the radio, TV, or branded tricycles, ${ }^{10}$ were intended to make eggs more desirable and increase caregivers' willingness to buy them and feed them to their children. Messaging through these channels also helps to alleviate any concerns caregivers have about feeding their children eggs by increasing consumer perception that eggs are easy, safe, and convenient for their children.

These ATL activities were supplemented with BTL activities, including retail messaging to raise the visibility of eggs at the point of purchase and give visual reminders to shoppers about the campaign. Community-based engagement activities aimed to increase knowledge about the benefits of eggs, as well as give peer-to-peer advice on how to prepare them. Television and radio spots were broadcast across the 23 local government areas of the state, timed in such ways to ensure simultaneous airing, thereby reinforcing messages across multiple channels. Retail and community activities targeted residents with young children in the Chikun, Kaduna North, and Kaduna South areas.

The type and location of these activities also considered the religious, social, and cultural differences between the northern and southern regions of the state - with the north being predominately Muslim and more conservative, and the south's population being a mix of Christians and Muslims and more liberal.

\section{ABOVE-THE-LINE CAMPAIGN ACTIVITIES}

The frequency and reach of the ATL campaign were benchmarked against the reach of commercially branded foods advertised in Kaduna State, to ensure the campaign would break through the volume of advertising messages to which consumers were exposed. Both radio and television media campaigns were designed to target female caregivers between 19 and 50 years of age, as they are the primary caregivers in Kaduna State. Most of the budget was dedicated to radio, as it offered the highest penetration and best medium to target the chosen populations. Additionally, out-of-home tricycle branding aimed to broadly increase campaign awareness. A further explanation of each activity is provided below.

\footnotetext{
10 Tricycles are motorised rickshaws used for public transit as a fast way to get around and are commonly seen across Kaduna state.
} 
Radio: Radio publicity was designed to improve awareness of the benefits of consuming eggs. With a presence in the home, community, markets, businesses, and outdoors, radio is a ubiquitous part of life in Nigeria and a critical aspect of the 'Eggs Make Kids' campaign. While both men and women listen to radio programming, the campaign radio strategy uses radio publicity by female on-air personalities, radio dramas, jingles, and targeted ad placement during women-centric programming because women are the primary caregivers of young children in Kaduna State. This communication channel drives awareness and discussion around egg consumption for children by using uplifting, positive, and fun messaging and jingles to the tune of traditional folklore songs that prompt caregivers and children to sing along. A sample transcript from a radio advertisement is displayed in Figure 5 .

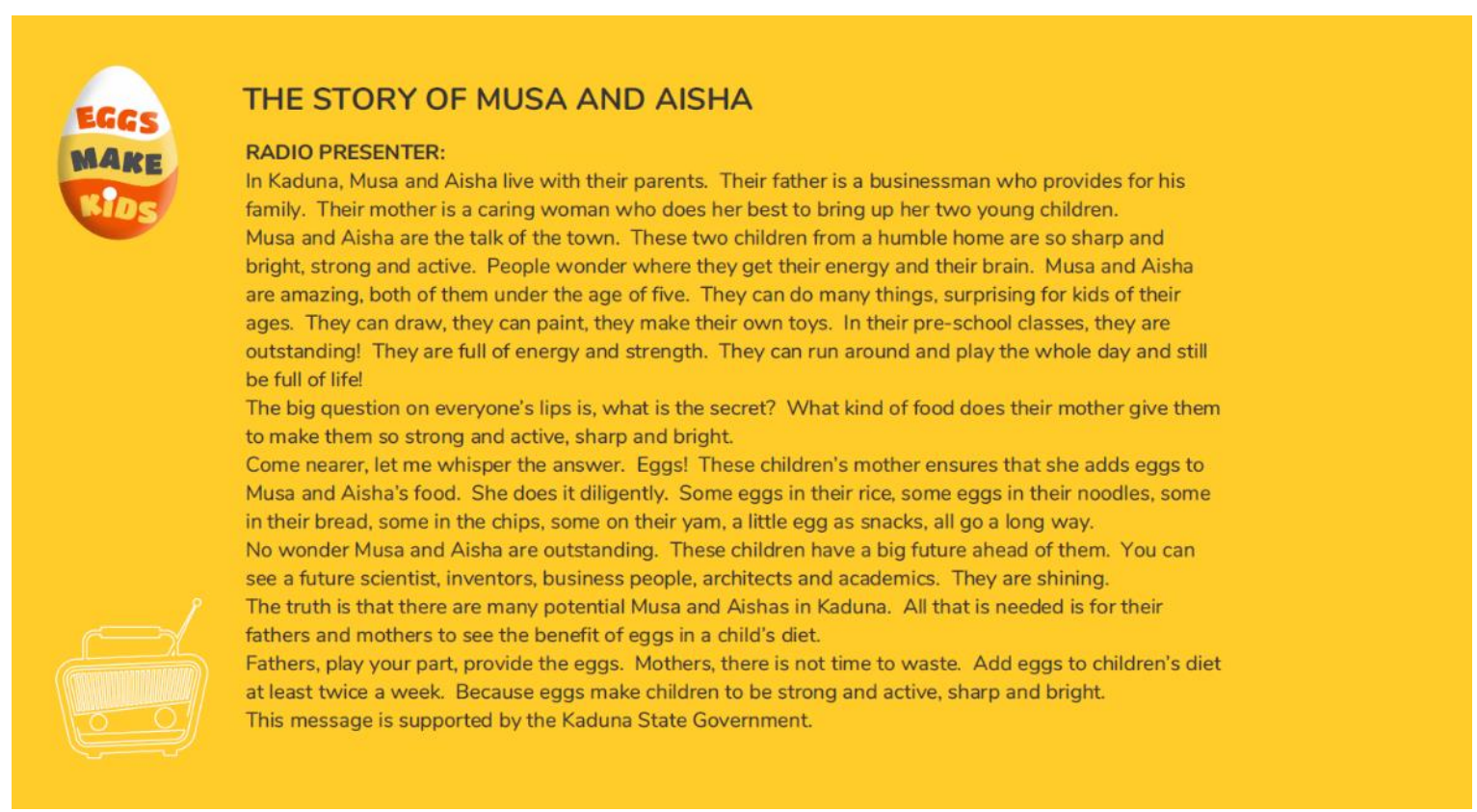

Figure 5: A transcript (in English) from radio publicity to encourage caregivers to feed their children eggs to make them strong and active, sharp and bright. 
Television: Television commercials are used to deliver campaign messages to caregivers that eggs are easy, safe, and convenient for their children through brief spot deployments during high-viewership times. By using 15- and 30second commercials during dramas, soap operas, and Kannywood ${ }^{11}$ movies, the programme maintains cost effectiveness and optimises reach. Additional television promotion is done by integrating campaign content into cooking shows, Abincin Dadi and Tukunyan Arewa, which feature egg-based recipes and techniques for integrating eggs into traditional Nigerian recipes.

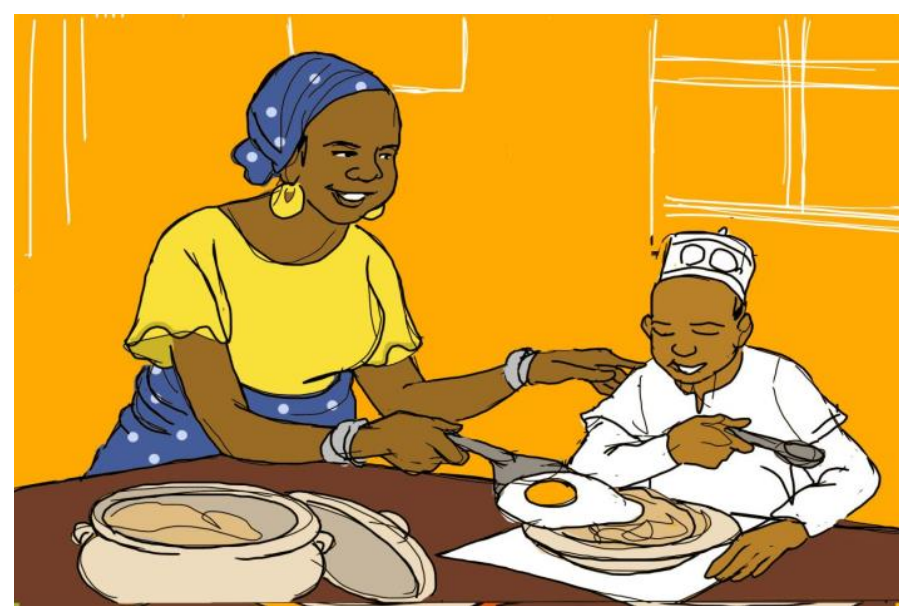

Figure 6: A sample image from the "Eggs Make Kids" TV storyboard.

The shows also mention 'Eggs Make Kids' messages during programming.

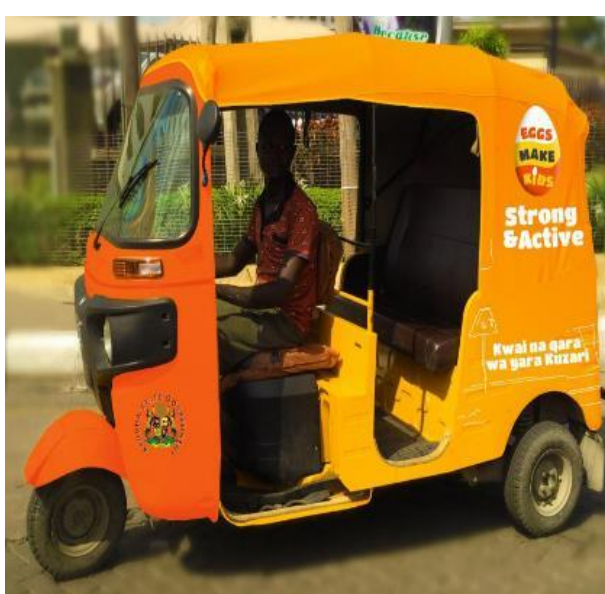

Figure 7: An example of a branded 'Kaka' or tricycle being driven around Kaduna State
Tricycle Branding: Tricycle transportation is commonly used in the local area, especially by women, and tricycles are visible in the streets and in the community. Tricycle branding also improves awareness of the benefits of consuming eggs.

\section{BELOW-THE-LINE CAMPAIGN ACTIVITIES}

The BTL campaign focuses on increasing the willingness of caregivers to purchase eggs and feed them to children through community-based activities focused on the benefits of feeding eggs to children, increasing knowledge on how to cook eggs, and improving the visibility of eggs as the point of purchase.

Community-Based Shows: Neighbourhood open market and compound ${ }^{12}$ shows gather up to 150 participants together for egg-focused education, music, drama performances, radiolive broadcasts, and cooking demonstrations. Neighbourhood open market shows engage male and female caregivers and encourage them to purchase eggs in the market. In conservative Muslim communities where some women may not leave the home regularly,

\footnotetext{
${ }^{11}$ Kannywood is the Hausa Language film industry of Northern Nigeria, based in Kano State.

${ }^{12} \mathrm{~A}$ compound is a cluster of houses in an enclosed area inhabited by extended family members.
} 
female-led compound shows deliver accessible entertainment and education to encourage women to regularly feed their young children eggs and other nutrient-dense foods.

Compound shows are attended by those living in the compound and their neighbours.

Door-to-Door Activities: 'Pantry raids' are designed as mystery visits that provide egg rewards for families who have eggs (or eggshells) in the home and report feeding eggs to their children. Families choose their reward: more eggs or plastic cooking bowls.

Point-of-Purchase Materials: Strategically placed promotional materials are used by egg vendors to make eggs and their benefits for children more visible at their stalls, encouraging parents to purchase eggs. More than 3,455 promotional materials (including hats, aprons, flags, bunting, umbrellas, posters (sample shown at right), banners and z-cards) are used by more than 1,500 vendors.

Primary Health Centre Promotions: The Nutrition Focal Person from three Local Government Agencies spoke to caregivers attending appointments at five hospitals about the benefits of eggs as a nutritious food for young children. State-supported promotional materials were placed at the hospitals and allowed for further messaging to reach caregivers.

School Programmes: Dramas, skits, and jingles engage children in 10 schools, educate them

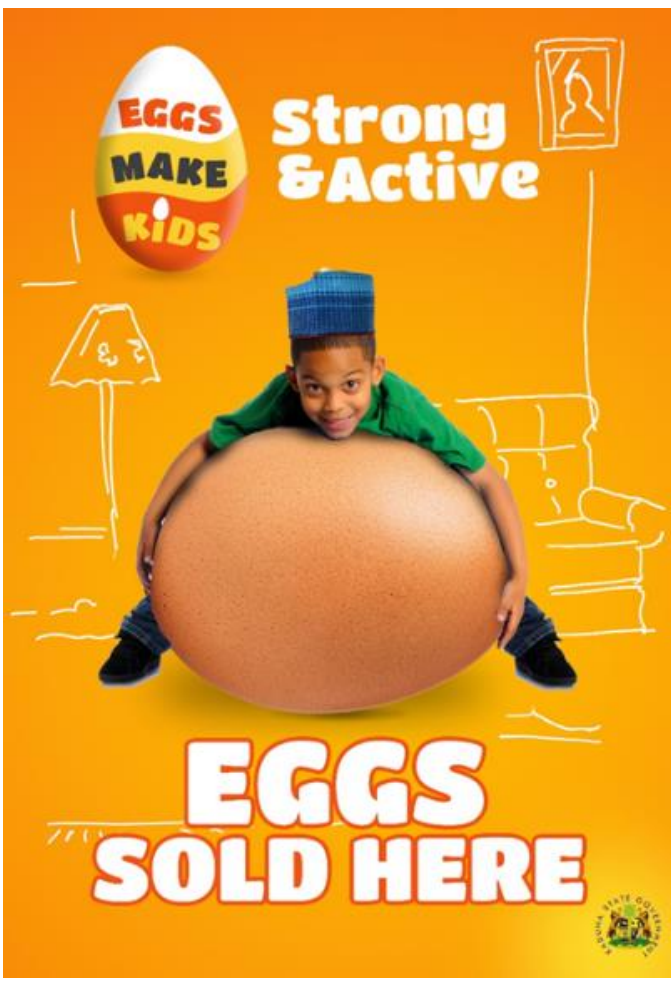

Figure 8: An example of a campaign poster in English about the health benefits of eggs, and promote campaign messaging in conjunction with a Kaduna State nutritionist. These activities aim to encourage children to ask parents and caregivers for eggs at home or in the market.

\section{PARTNER ENGAGEMENT AND COORDINATION}

GAIN has worked with a range of partners throughout the design and implementation processes, playing a coordinating role to ensure that each set of skills was utilised and that the campaign was developed in an integrated and holistic way and launched on time. Aligning priorities, providing a supportive framework and structure, and capitalising on the strengths of different organisations and teams were essential to create a collaborative partnership capable of creating, communicating, and delivering a shared vision and message to improve young children's diets.

One key set of partners were the creative and testing agencies-an atypical type of partner for a nutrition intervention. Three creative agencies (STB McCann, System1 Research, and Film Factory) were employed to develop, test, and launch the campaign materials, with 
oversight, support, and input from GAIN. The ongoing campaign delivery is a collaborative effort between GAIN staff and the Nigeria-based GDM Group (BTL) and PHD Media (ATL). GDM Group also provides vendor support, collects and reports on monthly egg sales figures, and performs Mobile Egg Truck operations (see Box 3).

The government of Kaduna State has also been closely involved in the 'Eggs Make Kids' campaign since its inception. Before the launch in October 2019, state representatives played a key role in vetting and approving campaign materials to ensure that the images and messages were tangible and meaningful for the residents of Kaduna State. In a show of support and programme endorsement, the Kaduna State seal appears on campaign materials. During the campaign, state representatives actively participate in project and campaign conversations and launch activities, and the Kaduna State Nutrition Office officials have taught about the benefits of eggs in schools and community-based activities. A major aim for future engagement with state-level leadership is to develop a financial sustainability strategy for the project.

Another key local partner is the Poultry Association of Nigeria (PAN), a voluntary organisation that aims to observe, understand, and support egg supply and the market environment in Nigeria. PAN was a key partner in the launch of the Mobile Egg Truck, and GAIN has been working closely with PAN to identify

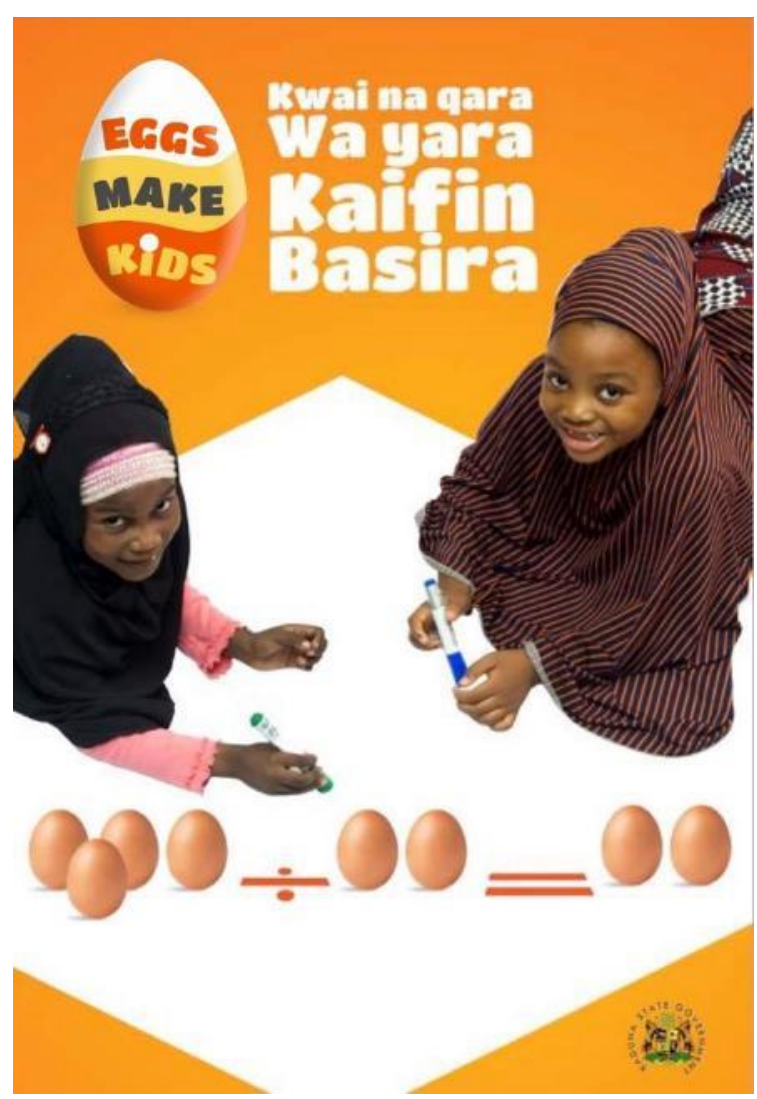

Figure 6: An example of a campaign picture in Hausa supply gaps to ensure seamless flow from egg producers to the point of sale and price stabilisation of eggs. These measures intend to increase long-term project sustainability.

Various monitoring and evaluation partner organisations have provided consultation and performed context analysis, baseline assessments (Oxford Policy Management), and an early evaluation of the 'Eggs Make Kids' campaign via mobile survey technologies (Viamo). A final impact evaluation is also being planned in conjunction with a partner organisation.

In addition to these formal partnerships, an informal and complementary partnership with Alive and Thrive also emerged from shared work using ASF to improve IYCF practices in Kaduna State. Using a communication strategy with harmonised messaging between the two organisations is likely to increase the reach (and efficiency) of the campaign messaging. 


\section{PRELIMINARY RESULTS AND MONITORING AND EVALUATION PLANS}

The short campaign timeframe (since October 2019 until, at the time of writing, August 2020) is likely too brief to identify sustained changes in egg consumption by young children.

However, the monitoring data collected was used to identify trends in egg purchasing and to respond to changes in the project's direction. Monthly tracking of both retail and vendor egg sales was used as an indicator of whether the campaign was resulting in increased household spending on eggs. Both sales figures and intake patterns are likely to have been impacted by market changes and social challenges experienced in response to the COVID-19 pandemic, although exact impacts are unknown (see Box 3). In the context of a global pandemic, community lockdown measures, egg supply variability, school closures and widespread unemployment, further analysis is needed to understand potential impacts on the campaign's performance. 


\section{BOX 3: ADAPTING IN RESPONSE TO COVID-19}

The COVID-19 pandemic resulted in a lockdown and school closures across Kaduna State. Community-based 'Eggs Make Kids' BTL activities stopped to comply with lockdown measures, and the movement of eggs and other supplies into and out of Kaduna State was slowed to protect public health. Farmers and wholesalers saw increases in egg wastage because of a sudden decrease in purchasing for school food and nutrition programmes. At the same time, local markets reported egg shortages because of a lack of supply, poor credit access, and limited distribution.

GDM Group, GAIN, and PAN coordinated efforts to reallocate eggs to markets experiencing shortages. A repurposed truck was used as a 'Mobile Egg Truck' to pick up eggs from farms and wholesalers, and then deliver them to community and neighbourhood markets. Outfitted with 'Eggs Make Kids' branding materials and playing campaign jingles, the Mobile Egg Truck continued to promote the campaign messages to engage caregivers even though formalised market shows and other BTL activities were not permitted.

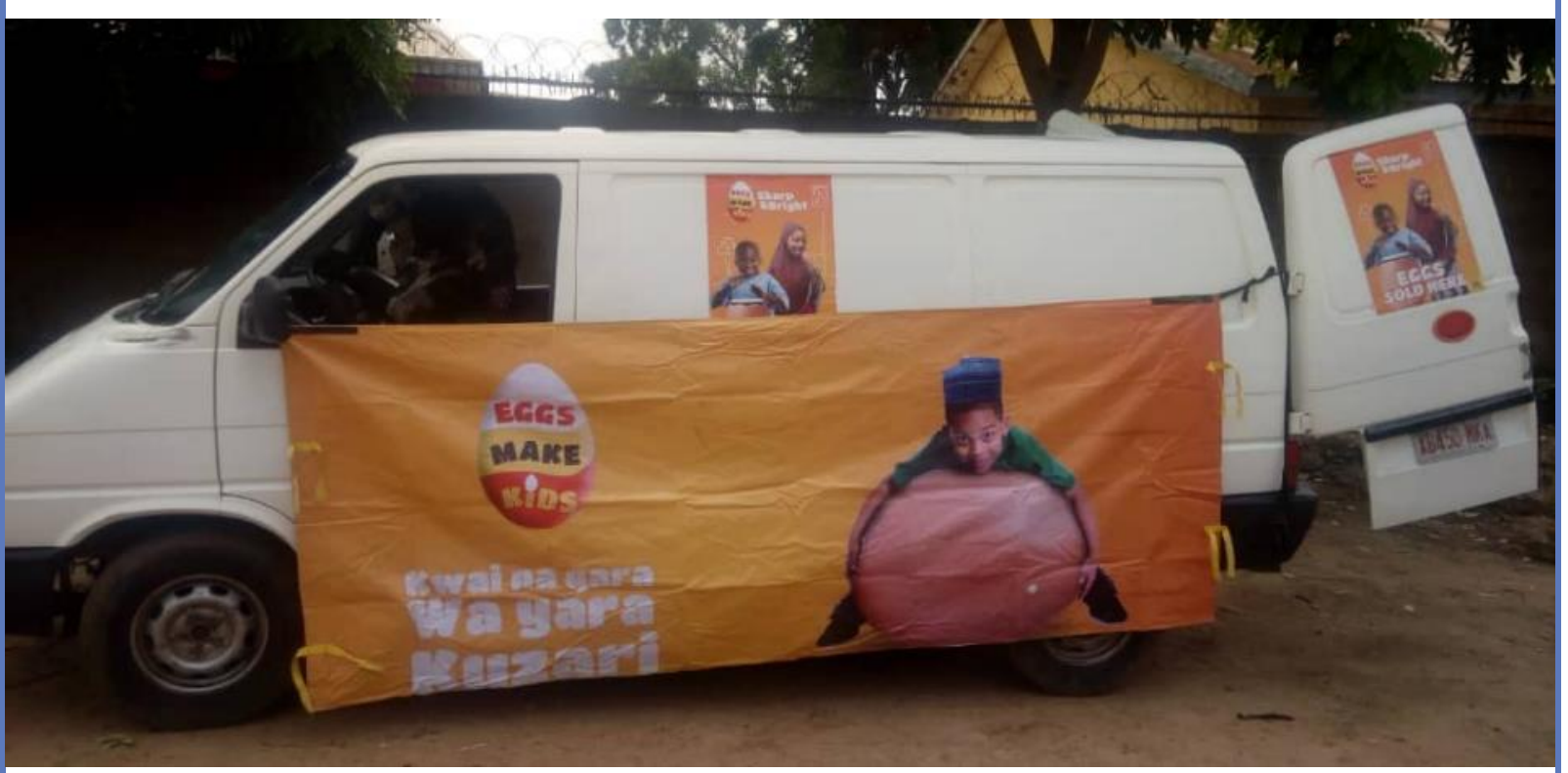

Other project adaptations due to COVID-19 included an increase in the frequency of radio spots delivering campaign messaging, an early launch of the next round of tricycle branding to re-engage caregivers with in-person branding as communities reopened, planning for future community-based BTL activities in compliance with state-level health and safety guidance, and consideration of increased engagement through employers, religious centres, and schools to continue to extend the reach and frequency of campaign messaging.

Whilst anthropometric or biological improvements and sustained changes in consumption are challenging to both measure and use to attribute the impact of the campaign, other 
measures are available. Preliminary results showed that the campaign was seen and understood by a majority of surveyed respondents within the target audience. According to annual monitoring data, more than 472,000 people were indirectly reached by the 'Eggs Make Kids' campaign in 2019. A mid-line mobile phone-based survey was conducted for two weeks in April and May of 2020 to explore the level of caregiver awareness of and exposure to the 'Eggs Make Kids' campaign. Using interactive voice responses, participants were asked to consent to participate in a short survey. To be included in the study, they were required to reside in Kaduna State, be between the ages of 19 and 50 years, care for a child under five years of age, and have seen and/or heard messaging from the 'Eggs Make Kids' campaign. With higher mobile ownership among men than women in Kaduna State, a retrospective gender screening question was added to achieve a fairly balanced gender ratio for the survey: $44.4 \%$ of respondents were male, and $55.6 \%$ were female.

Key results of the survey were as follows:

- Radio and Television Advertising: Whilst some participants reported hearing or seeing campaign materials unprompted, upon hearing the radio jingle during the survey, more than half of participants $(55.2 \%$; 260/471) reported having heard the 'Eggs Make Kids' campaign on the radio. Fewer participants reported seeing the campaign on television $(30.6 \% ; 144 / 471)$. These early results are promising and suggest that the campaign is reaching targeted caregivers.

- Promotion Activity Awareness: For participants in Chikun, Kaduna North, and Kaduna South areas (the areas in which BTL promotions were concentrated), most participants $(72.4 \%$; 314/434) reported seeing promotion activities for eggs in their neighbourhoods.

- Campaign Messaging Agreement: Most participants agreed that eggs make children strong and active (88.5\%; 417/471) and sharp and bright (77.3\%; 364/471).

- Changes in feeding behaviour: Such changes were less frequently reported, as expected. Only $57.5 \%$ (271/471) of caregivers reporting feeding their child(ren) eggs within the week prior to the study.

Since the start of the project, monthly and quarterly sales data have been collected and analysed. However, there are some limitations with using this data. Data were collected from both 940 retailers and 32 wholesalers, perhaps leading to some double-counting, which was difficult to reconcile without proper tracing. In addition, without historical sales data, it is difficult to understand the drivers of the sales trends, namely, seasonality, large procurement drives from institutional buyers (for example, to supply school feeding programmes), or price fluctuations. Finally, the COVID-19 pandemic has made it even more challenging to collect real-time data, creating gaps in the tracking. Continually assessing monthly and quarterly data may help to identify seasonal trends and patterns but increases or decreases in sales are difficult to attribute to the demand campaign alone. Retailers and field support staff have also reported subjective and qualitative increases in egg sales because of the campaign, but a causal link with the campaign is hard to demonstrate at this point in time. 
Further monitoring indicators include campaign exposure (including point-of-purchase marketing, market activations and shows, compound shows, tricycle advertising, and media advertising (radio, television)), reach of BTL campaign activities (including compound shows, neighbourhood advocacy, school-based events, and pantry raids), and participant responsiveness (including message recall, attractiveness of campaign materials, and agreement with campaign message).

A rigorous, mixed-methods endline evaluation is also planned. The evaluation will use a quasi-experimental research design, comparing results between and across states between baseline (collected in September 2019, before the campaign) and endline (to be completed just after the end of the campaign). The proposed evaluation includes sampling 2,500 households with at least one child ages six to 59 months. To measure diets for a cohort of children at baseline and endline, dietary intake data will be gathered for all children between six and 84 months of age. The change in egg consumption frequency will be evaluated, including the percentage of children consuming eggs at least one time per week and the number of eggs eaten per week per child aged six to 59 months. A willingness-to-pay assessment will also be performed using a discrete choice experiment (where participants will be asked to choose among foods commonly fed to children) as well as a contingent valuation (where participants will be asked about how much they are willing to pay for eggs). Using data collected before and after the campaign, the evaluation team plans to estimate of the impact of exposure to the ATL and BTL interventions on the weekly consumption of at least one egg, number of eggs purchased, and number of eggs consumed. A qualitative evaluation will determine to what extent social and cultural norms about eggs and perceptions of eggs have changed.

\section{LESSONS LEARNED}

Developing and implementing the novel, demand-creation approach used for the 'Eggs Make Kids' campaign brought to life GAIN's mission to make nutritious and safe food more desirable in a new way and fostered important organisational learning. In creating and implementing this new model, several important lessons were learned and later applied to improve creative agency management and engagement; to adapt monitoring practices to address real-time challenges, observations, and insights from the field; and to better predict enabling factors to ensure project success.

First, partnering with creative agencies is a new endeavour for GAIN, and this project helped GAIN hone processes for creative agency engagement and apply this knowledge to other projects. In response to early challenges ensuring timely deliverable submission and translating the concept into a cohesive campaign, GAIN developed an Agency Selection and Management toolkit and operationalised techniques to better identify, manage, and collaborate with creative agencies hired to develop and deliver successful demand-creation projects. The toolkit is used to support and facilitate decision-making and communication, from recruitment through the agency contract period. Furthermore, the project made clear that utilising numerous agencies' expertise, rather than limiting the number of agencies involved in a campaign, can facilitate execution at the field level and strengthen the quality of 
the project. Employing multiple agencies with different skills, however, is only practical and possible in conjunction with setting clear expectations and well-executed, well-organised project coordination efforts. These are particularly useful lessons to learn, as GAIN's work is the sum of its partnerships and alliances. This collaboration also provided creative agencies with the opportunity to develop skills in generating demand for nutritious foods.

Second, the implementing team learned that real-time monitoring, data collection, and communication allow for reflexivity, adaptability, and agility when challenges and opportunities inevitably arise during projects. While the impacts of a global pandemic would have been difficult to predict, having a presence on the ground with established communication channels ensured that the campaign (and egg supply) could continue to identify and respond to the needs of the vendors, wholesalers, and community.

Third, even at this early juncture, the 'Eggs Make Kids' campaign made clear several important design points that should be considered in future demand-creation campaigns. Rather than reliance on larger state- and national-level data, there is a critical need for timely access to current, local data. In this case, data from the baseline assessment were not yet available when the campaign was designed, meaning that limited recommendations could be incorporated into the design before the launch of the campaign. Earlier assessments are needed to better inform campaign designs, ensuring that a project is built around the current needs of the target population. Relevant information on affordability, food preferences, purchasing patterns, and food beliefs provides important insights to accurately predict how demand creation may influence purchasing patterns. Similarly, ensuring that the supply of the product of focus is adequate, affordable, and stable is vital.

Finally, this project was feasible because of the enabling environment provided and supported by Kaduna State. With an established egg supply and poultry aggregation network, governmental support, existing local nutrition programming, and sufficient local income for most consumers to reasonably purchase eggs regularly, GAIN was able to focus on using a demand-focused, product marketing approach to encourage caregivers to purchase eggs for their children. It would be possible to translate the knowledge and experience gained with the 'Eggs Make Kids' campaign to another locale or to apply similar techniques to other foods. However, an integrated approach that encompasses consumer demand creation, ensures food affordability and accessibility, and promotes the production of a safe and nutritious food would be required. By holistically working across these three strategic elements, GAIN (and other organisations interested in such approaches) can ensure that projects are designed to support the food system, with the goal of improving diets for children around the world.

\section{CONCLUSION}

In conceiving the 'Eggs Make Kids' campaign, GAIN tested the feasibility of a new approach to increase consumption of eggs among young children. Using commercial marketing techniques to generate demand for a fresh, unbranded nutritious food, the 'Eggs Make Kids' campaign builds on a universal hope parents have: for their children to be healthy, active, 
and bright. The intended aspirational, emotional response to eggs was conceived to be culturally relevant to the experience of parents of children under age five, featuring children in a way that creates an immediate connection with the viewer/listener and elicits the feeling 'this is how I want us to be.'

While the campaign is ongoing, great potential exists to employ the project's lessons learned and demand-creation principles in conjunction with in-depth consumer insights to expand the campaign further across Nigeria or into other countries. In addition, there is an opportunity to use the insights from this project to promote other nutritious foods. Expanding the project into other regions or exploring opportunities to promote other foods may require work on product supply, to understand and address both availability and affordability. Yet demandcreation activities can still play a critical role in promoting fresh, unbranded, and nutritious foods to improve dietary intake among young children. 


\section{REFERENCES}

1. Lusk J, Roosen J, Shogren J. The Oxford handbook of the economics of food consumption and policy (Oxford handbooks). Oxford, UK; New York, USA: Oxford University Press; 2011.

2. Hill D. Emotionomics. London, UK: Kogan Page; 2010.

3. Aschemann-Witzel J, Perez-Cueto FJ, Niedzwiedzka B, Verbeke W, Bech-Larsen T. Lessons for public health campaigns from analysing commercial food marketing success factors: a case study. BMC Public Health. 2012 Dec;12(1):139.

4. California Milk Processor Board. Got Milk? [Internet]. Got Milk. 2020 [cited 2020 Sep 13]. Available from: https://www.gotmilk.com/

5. VegPower. Eat Them To Defeat Them [Internet]. 2020 [cited 2020 Sep 22]. Available from: https://vegpower.org.uk/

6. United Nations Children's Fund (UNICEF). Malnutrition in Children [Internet]. UNICEF DATA. 2020 [cited 2020 Jul 12]. Available from: https://data.unicef.org/topic/nutrition/malnutrition/

7. United Nations Children's Fund (UNICEF), World Health Organization (WHO), the International Bank for Reconstruction and Development/The World Bank Group. Levels and trends in child malnutrition: key findings of the 2020 edition of the Joint Child Malnutrition Estimates [Internet]. Geneva: World Health Organization; 2020. Available from: https://data.unicef.org/resources/jme-report-2020/

8. Food Systems Dashboard [Internet]. Food Systems Dashboard. 2020 [cited 2020 Sep 9]. Available from: https://foodsystemsdashboard.org/

9. National Bureau of Statistics (NBS), National Population Commission (NPopC), United Nations Children's Fund (UNICEF). National Nutrition and Health Survey (NNHS) 2018, Nigeria [Internet]. Abuja, Nigeria: National Bureau of Statistics and United Nations Children's Fund; 2018 Jun [cited 2020 Jun 29]. Available from: https://www.unicef.org/nigeria/sites/unicef.org.nigeria/files/2019-02/NNHS_2018.pdf

10. Black RE, Victora CG, Walker SP, Bhutta ZA, Christian P, de Onis M, et al. Maternal and child undernutrition and overweight in low-income and middle-income countries. The Lancet. 2013 Aug;382(9890):427-51.

11. Krasevec J, An X, Kumapley R, Bégin F, Frongillo EA. Diet quality and risk of stunting among infants and young children in low- and middle-income countries. Matern Child Nutr. 2017 Oct;13:e12430.

12. White JM, Bégin F, Kumapley R, Murray C, Krasevec J. Complementary feeding practices: Current global and regional estimates. Matern Child Nutr. 2017 Oct;13:e12505.

13. World Health Organization (WHO). Essential nutrition actions: mainstreaming nutrition through the life-course. Geneva: World Health Organization; 2019.

14. Pan American Health Organization (PAHO), World Health Organization (WHO). Guiding principles for complementary feeding of the breastfed child [Internet]. Geneva; 2003 [cited $2020 \mathrm{Jul}$ 13]. Available from: 
https://www.who.int/nutrition/publications/guiding_principles_compfeeding_breastfed. pdf

15. Prado EL, Maleta K, Caswell BL, George M, Oakes LM, DeBolt MC, et al. Early Child Development Outcomes of a Randomized Trial Providing 1 Egg Per Day to Children Age 6 to 15 Months in Malawi. The Journal of Nutrition. 2020 Apr 14;nxaa088.

16. Iannotti LL, Lutter CK, Stewart CP, Gallegos Riofrío CA, Malo C, Reinhart G, et al. Eggs in Early Complementary Feeding and Child Growth: A Randomized Controlled Trial. Pediatrics. 2017 Jul;140(1):e20163459.

17. Iannotti LL, Chapnick M, Nicholas J, Gallegos-Riofrio CA, Moreno P, Douglas K, et al. Egg intervention effect on linear growth no longer present after two years. Matern Child Nutr [Internet]. 2020 Apr [cited 2020 Jun 18];16(2). Available from: https://onlinelibrary.wiley.com/doi/abs/10.1111/mcn.12925

18. Baum JI, Miller JD, Gaines BL. The effect of egg supplementation on growth parameters in children participating in a school feeding program in rural Uganda: a pilot study. Food \& Nutrition Research. 2017 Jan;61(1):1330097.

19. Stewart CP, Caswell B, lannotti L, Lutter C, Arnold CD, Chipatala R, et al. The effect of eggs on early child growth in rural Malawi: the Mazira Project randomized controlled trial. The American Journal of Clinical Nutrition. 2019 Oct 1;110(4):1026-33.

20. Morris SS, Beesabathuni K, Headey D. An egg for everyone: Pathways to universal access to one of nature's most nutritious foods. Matern Child Nutr. 2018 Oct;14:e12679.

21. Headey DD, Alderman HH. The Relative Caloric Prices of Healthy and Unhealthy Foods Differ Systematically across Income Levels and Continents. The Journal of Nutrition. 2019 Nov 1;149(11):2020-33.

22. National Bureau of Statistics (NBS), United Nations Children's Fund (UNICEF). Multiple Indicator Cluster Survey 2016-2017, Survey Findings Report [Internet]. Abuja, Nigeria: National Bureau of Statistics and United Nations Children's Fund; 2017 [cited 2020 Jun 29]. Available from: http://somlpforr.org.ng/wp-content/uploads/2017/12/MICSNational-Report.pdf

23. World Health Organization (WHO). Indicators for assessing infant and young child feeding practices: Part 1- Definitions. Washington, D.C.: World Health Organization (WHO); 2008.

24. Food and Agriculture Organization (FAO) Nigeria. Nigeria Food Security and Vulnerability Survey 2016 [Internet]. FAO; 2016 Nov [cited 2020 Jun 22]. Available from: https://reliefweb.int/sites/reliefweb.int/files/resources/food_security_livelihoods_and_vul nerability_assessment-final_draft_report_of_2016_fsvs_fao_nbs_dec_1-2.pdf

25. National Population Commission (NPC) [Nigeria] and ICF. Nigeria Demographic and Health Survey 2018 [Internet]. Abuja, Nigeria and Rockville, Maryland, USA: NPC and ICF; 2019 Oct [cited 2020 Sep 9]. Available from: https://dhsprogram.com/pubs/pdf/FR359/FR359.pdf

26. System1 Research, Global Alliance for Improved Nutrition (GAIN). Next Generation Predictive Markets: Nigeria Egg Promotion Communication Test. 2019 Jan; London, UK. 